\title{
THE EFFECT OF EXOGENOUS OXYTOCIN ON CORPUS LUTEUM FUNCTION IN THE COW
}

\author{
LLOYD E. DONALDSON AND ALBERT TAKKEN \\ C.S.I.R.O., Division of Animal Physiology, Cunningham Laboratory, \\ Mill Road, St. Lucia, Brisbane
}

(Received 8th December 1967, revised 7th March 1968)

Summary. Seventy-seven Hereford cows were used to study the effects of oxytocin $(0,2,6$ or 18 USP units/100 lb live weight) on corpus luteum function (net weight, progesterone concentration and total progesterone content). Oxytocin was injected in the morning (a.m.) or evening (p.m.) according to four injection regimes. Calling day of oestrus Day 0, oxytocin was injected on Days 2 to 5 and the corpus luteum collected on Day 5 (regime 1) or Day 9 (regime 2). Oxytocin was injected on Days 2 to 7 (regime 3 ) or 2 to 9 (regime 4), and the corpus luteum collected on Day 9.

There was no effect of time of injection on corpus luteum net weight, progesterone concentration or total progesterone content over all doses and regimes. However, within doses 2 and 6 units, corpus luteum total progesterone was less affected by p.m. than a.m. injection. The opposite effect was observed when 18 units oxytocin injected a.m. in regime 2 did not reduce corpus luteum total progesterone to the same extent as in other high dosage treatment groups.

The 2 units dose of oxytocin stimulated total progesterone content of corpora lutea in regime 2. Increase in the dose or number of days of injections reduced corpus luteum net weight, progesterone concentration and total progesterone. A significant dose-response relation was demonstrated between corpus luteum net weight, progesterone concentration and total progesterone and dose of oxytocin when oxytocin was injected on Days 2 to 5 (p.m.) and the response measured on Day 9; or when oxytocin was injected either a.m. or p.m. on Days 2 to 7 or 2 to 9 and the response measured on Day 9.

It was concluded that there may be a diurnal response in corpus luteum functions to oxytocin injections and a critical time on Day 5 through which injections must be made to elicit a maximum dose response in corpus luteum weight, progesterone concentration and progesterone content.

\section{INTRODUCTION}

Armstrong \& Hansel (1959) found that daily oxytocin injections during the first third of the oestrous cycle in cows reduced cycle length to 8 to 12 days. 
Oxytocin injections begun on Day 2 of the cycle reduced the weight and progesterone content of corpora lutea examined on Days 7 and 10 of the cycle, but not of those examined on Day 4 (Simmons \& Hansel, 1964; Donaldson, Hansel \& Van Vleck, 1965).

Mares \& Casida (1963) reported increased progesterone concentration in Day-14 corpora lutea following oxytocin injections on Days 12 and 13. Oxytocin injected early in oestrus hastened ovulation in the cow by $5 \mathrm{hr}$ (Hansel, Armstrong \& McEntee, 1958) and reduced the total pituitary gonadotrophin to about half (Donaldson et al., 1965). Pituitary gonadotrophin levels were reduced on Day 7 but not on Day 4, following oxytocin injections on Days 2 to 7 or 2 to 4 respectively. The total progesterone content of corpora lutea in these heifers on Days 4 and 7 was negatively correlated $(-0.75)$ with pituitary gonadotrophin in untreated heifers, but positively correlated in oxytocintreated heifers $(0.78)$. The positive correlation in treated animals was interpreted to mean that pituitary gonadotrophin levels were representative of plasma levels which were directly limiting progesterone content of the corpus luteum. The negative correlations in untreated animals represented pituitary storage of gonadotrophin (Donaldson et al., 1965).

It was concluded that oxytocin has an effect on the pituitary gland and the ovary. It is possible that oxytocin released during milk let-down in lactating cows (Turner, 1960) may exert an effect on the pituitary or ovary and affect the resumption of oestrus. Post partum anoestrus is an important problem in Australian beef cattle (Donaldson, 1962) so it was considered useful to study further the effects of oxytocin on ovarian function. This was done in the cycling heifer as it was believed this was a necessary prelude to any more expensive investigation in the post partum cow.

\section{MATERIALS AND METHODS}

\section{Cattle and management}

A group of seventy-seven Herefords was used, seventy were nonparous normally-cycling heifers, aged 15 to 30 months, weighing 500 to $850 \mathrm{lb}$. The remaining seven were multiparous aged cows. Animals were tested with a bull or other heifers 2 or 3 times a day to detect oestrus, and were under general observation during working hours. Following detection of oestrus, animals were allotted to treatments in such a way that one replicate was completed at a time. Heifers were allowed a normal cycle between treatments. Forty-four animals were used once, twenty-four twice, eight three times and one four times.

\section{Treatments}

Oxytocin (Crookes Laboratories Ltd) was injected at four dose rates $(0,2$, $6,18 \mathrm{USP}$ units/100 lb live weight) at two times of the day, according to four injection regimes in an incomplete factorial design. Injections were made between 09.00 and 10.00 hours (a.m.) or between 16.00 and 17.00 hours (p.m.). Calling day of oestrus Day 0, the regimes were: 
1. Injections Days 2 to 5 , the corpus luteum (CL) being removed on Day 5 (2 to $5 / 5)$.

2. Injections Days 2 to 5 the cL being removed on Day 9 (2 to $5 / 9$ ).

3. Injections Days 2 to 7 the cL being removed on Day 9 ( 2 to $7 / 9$ ).

4. Injections Days 2 to 9 the cL being removed on Day 9 ( 2 to $9 / 9$ ).

There were five replicates. Cows were not injected with the 0,2 or 6 units oxytocin in regime 3 , nor with 0 units in regime 2 . Doses of oxytocin were calculated to the nearest $50 \mathrm{lb}$ live weight from weighings conducted at least every 2 weeks.

\section{Removal of corpora lutea}

Corpora lutea were removed a.m. or p.m. by laparotomy through the flank under paravertebral anaesthesia or through a dorsal incision in the anterior wall of the vagina. The GL was dissected out of the ovary by finger dissection or with blunt-pointed scissors. The cL was weighed immediately after removal from the cow.

After cutting in half, any cyst fluid was drained from the CL and the net weight recorded. Half-gram aliquots of tissue were placed in $95 \%$ ethanol and stored below $0^{\circ} \mathrm{C}$ until their progesterone content was determined. A piece of CL was fixed in Bouin's solution for histological examination. Sections were cut at $6 \mu$ and stained with haematoxylin and eosin.

Corpora lutea were not removed from animals that came into oestrus during the treatment period. For the purpose of statistical analysis these corpora were given a net weight of $0.5 \mathrm{~g}$, a progesterone concentration of $1 \mu \mathrm{g} / \mathrm{g}$, and a total progesterone content of $1 \mu \mathrm{g}$. This was because dissection of such corpora from the ovary is difficult and their progesterone content is undetectable by the technique used.

\section{Chemical analysis of progesterone}

Progesterone was measured by a modification of the methods of Staples \& Hansel (1961) and Armstrong, O'Brien \& Greep (1964). The cL sample in $95 \%$ ethanol was cut into small pieces with scissors and transferred into a $250-\mathrm{ml}$ round-bottom flask (RBF) after the addition of $0.002 \mu \mathrm{c} \cdot\left[4-{ }^{14} \mathrm{C}\right]$ progesterone. Fifty $\mathrm{ml}$ of $95 \%$ ethanol was added, then refluxed for $30 \mathrm{~min}$, filtered and the filtrate dried under vacuum in a rotary film evaporator in a water bath at $60^{\circ} \mathrm{C}$. The RBF containing the alcohol extract was rinsed with 1 to $1.5 \mathrm{ml}$ of benzene:dichloromethane $(1: 1)$. Three unknown samples and a standard $10 \mu \mathrm{g}$ progesterone in $20 \mu \mathrm{l}$ ethanol were spotted under a stream of warm air onto a thin-layer plate coated with silica $G$. The samples were spotted in one line about $3 \mathrm{~cm}$ from one edge. Each spot was allowed to diffuse out in a circle approximately $2.0 \mathrm{~cm}$ in diameter. The $\mathrm{RBF}$ was rinsed with a further 1.0 and $0.5 \mathrm{ml}$ of benzene: dichloromethane $(1: 1)$ which were added to the initial spot on the plate. The chromatogram was developed first in benzene: dichloromethane $(1: 1)$ then in dichloromethane:diethyl ether $(5: 2)$ in the same direction.

The progesterone spots were located and marked under ultra-violet light 


\begin{tabular}{|c|c|c|c|c|c|c|c|c|}
\hline \multirow{3}{*}{\multicolumn{2}{|c|}{ 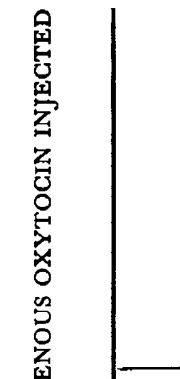 }} & \multirow{3}{*}{ 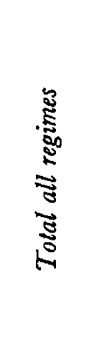 } & 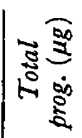 & 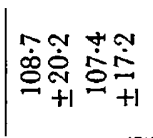 & 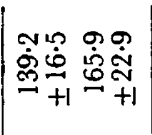 & 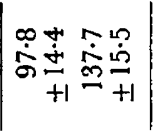 & 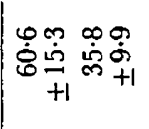 & 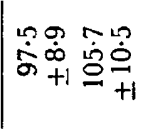 \\
\hline & & & $\frac{50}{20 \frac{00}{20}}$ & 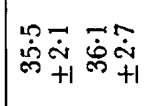 & 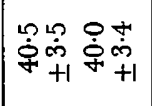 & 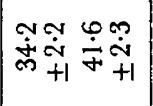 & 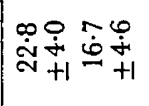 & 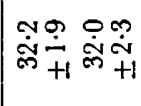 \\
\hline & & & 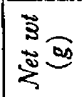 & 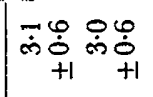 & 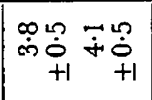 & 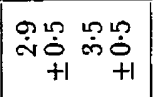 & $\underset{+1}{\stackrel{\sim}{\sim} \dot{0}} \stackrel{\sim}{\dot{0}} \dot{0}$ & 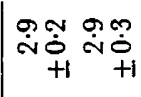 \\
\hline \multirow{14}{*}{ 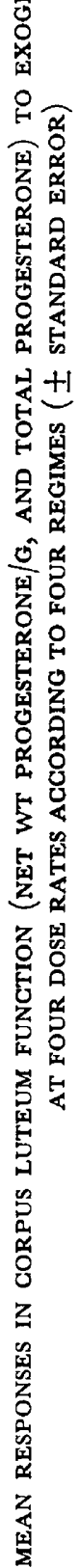 } & \multirow{12}{*}{ 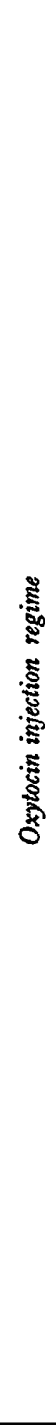 } & \multirow{3}{*}{ 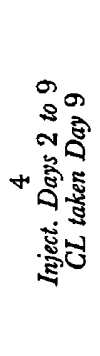 } & 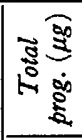 & 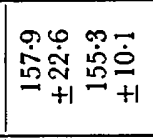 & 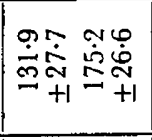 & 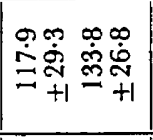 & 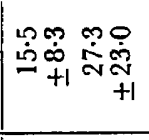 & $\mid \begin{array}{l}\infty \\
\dot{0} \dot{0} \\
\dot{0} \\
\dot{0}\end{array}$ \\
\hline & & & $\frac{100}{20}$ & $\dot{\dot{m}} \underset{+1}{\dot{\sim}} \stackrel{\dot{\varphi}}{\dot{m}}$ & 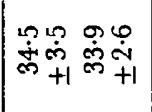 & 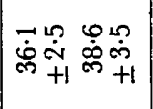 & 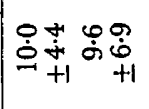 & 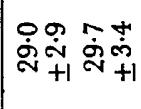 \\
\hline & & & 蔦 & 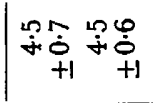 & $\mid \begin{array}{cc}\infty & 0 \\
\dot{m} & 0 \\
+1 & 0 \\
+1 & 0 \\
+1\end{array}$ & 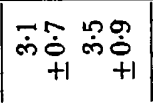 & 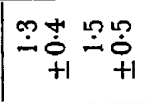 & 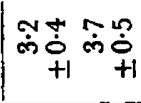 \\
\hline & & \multirow{3}{*}{ 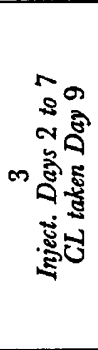 } & 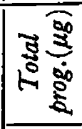 & & & & 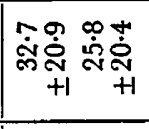 & 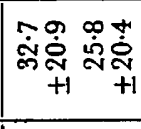 \\
\hline & & & $\frac{500}{200}$ & & & & 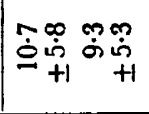 & 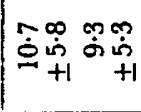 \\
\hline & & & 这 & & & & 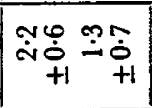 & 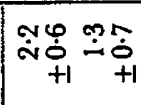 \\
\hline & & & 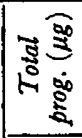 & & 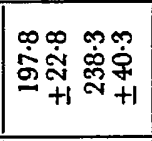 & 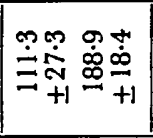 & 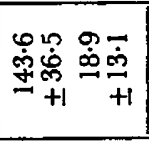 & 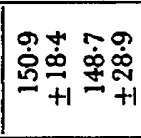 \\
\hline & & & कृष & & 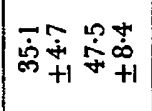 & 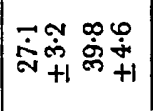 & $\overrightarrow{\dot{q}} \underset{+1}{\stackrel{9}{\dot{\omega}} \dot{m}}+1$ & 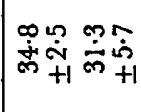 \\
\hline & & & 离 & & 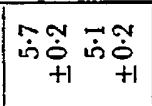 & 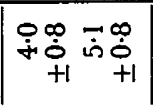 & 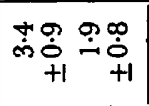 & $\underset{+1}{+0}$ \\
\hline & & \multirow{3}{*}{ 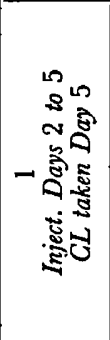 } & 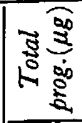 & 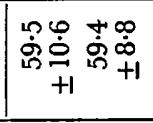 & 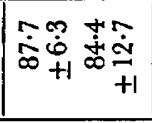 & 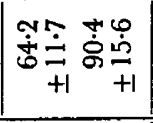 & 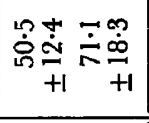 & 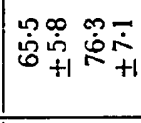 \\
\hline & & & 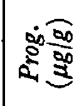 & 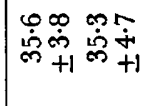 & 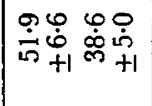 & 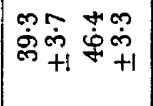 & 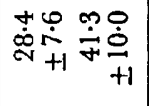 & 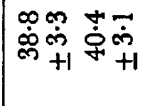 \\
\hline & & & $\frac{\overrightarrow{3}}{\vec{\pi}}$ & $\stackrel{\varphi}{\dot{\varphi}} \underset{+}{\dot{\phi}} \stackrel{\varphi}{\dot{\varphi}} \underset{+1}{\dot{\phi}}$ & 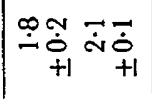 & $\left|\begin{array}{ccc}x & 0 & 0 \\
-\dot{0} & \dot{\sim} & 0 \\
+1 & & +1\end{array}\right|$ & 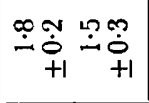 & 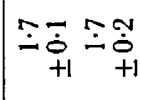 \\
\hline & \multicolumn{3}{|c|}{ 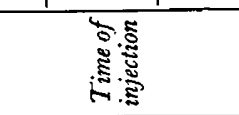 } & 突 & $\begin{array}{ll}\dot{g} & \dot{\Xi} \\
\text { ¿ }\end{array}$ & 岳 & 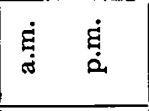 & 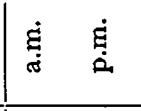 \\
\hline & \multicolumn{3}{|c|}{ ڤั } & 0 & $\infty$ & 0 & $\infty$ & 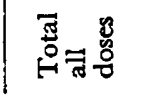 \\
\hline
\end{tabular}


and scraped off, eluted with ethanol and quantitatively determined on a Shimadzu QV-50 spectrophotometer as described by Armstrong et al. (1964).

An Allen correction factor was applied to the readings at 225, 240 and 255 $\mathrm{m} \mu$ to reduce influences of possible non-specific contaminants. If the sample did not show a peak at $240 \mathrm{~m} \mu$ it was rechromatographed, or the progesterone content determined on a duplicate sample of CL. Aliquots of the ethanol eluate were assessed for radio-activity on a scintillation spectrometer. The average recovery of the added $\left[4-{ }^{14} \mathrm{C}\right]$ progesterone was $47 \pm 5 \%$. All samples were corrected to $100 \%$ recovery.

\section{RESULTS}

The mean ( \pm standard error of the mean) net weight, progesterone concentration and total progesterone content of corpora lutea are listed for each treatment in Table 1. The data were analysed by analysis of variance and linear coefficients were calculated for the dose response relationships over doses 2, 6 and 18 units of oxytocin.

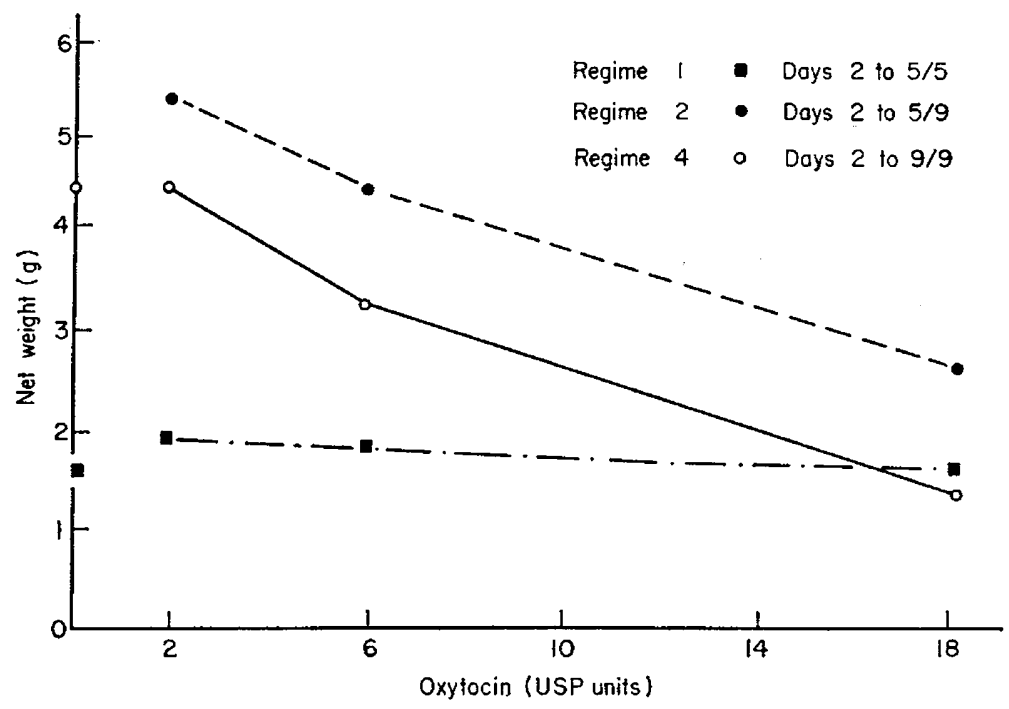

Text-Fig. 1. The dose-response relationships between net weight of the corpus luteum and dose of oxytocin injected according to three injection regimes.

Accumulating results over all injection regimes and all dose rates, there was no effect of time of injection on corpus luteum net weight $(2 \cdot 9 \pm 0 \cdot 2$, and $2.9 \pm 0.3 \mathrm{~g} \pm$ S.E. for a.m. and p.m. injections respectively), progesterone concentration $(32.2 \pm 1.9$ and $32.0 \pm 2.3 \mu \mathrm{g} / \mathrm{g})$ or total progesterone content $(97 \cdot 5 \pm 8 \cdot 9$ and $105 \cdot 7 \pm 5 \mu \mathrm{g})$.

\section{Corpus luteum net weight}

The linear coefficients for net weight and dose of oxytocin were not significant in regime $1(-0.032)$ but the coefficients were highly significant in 
regimes $2(-0 \cdot 294)$ and $4(-0 \cdot 325)$. The linear coefficients for regimes 2 and 4 were equal and both were significantly smaller than regime $1 \quad(P<0.001)$ (Text-fig. 1). Within the high dose of oxytocin groups (18 units) the net weight of corpora lutea was the same for all regimes (1 to 4) (Table 1).

There was a significant time $\times$ dose $\times$ regime interaction for corpus luteum progesterone concentration and progesterone content. These data were therefore analysed within each time $\times$ regime over the three doses of oxytocin $(2,6$ and 18 units).

\section{Corpus luteum progesterone concentration}

In regime 1 , the linear coefficient for animals injected a.m. $(-1 \cdot 338)$ for progesterone concentration and dose of oxytocin was significant $(P<0.01)$ and smaller $(P<0.05)$ than the non-significant linear coefficient for animals injected p.m. (0.033) (Text-fig. 2). In regime 2, the p.m. linear coefficient

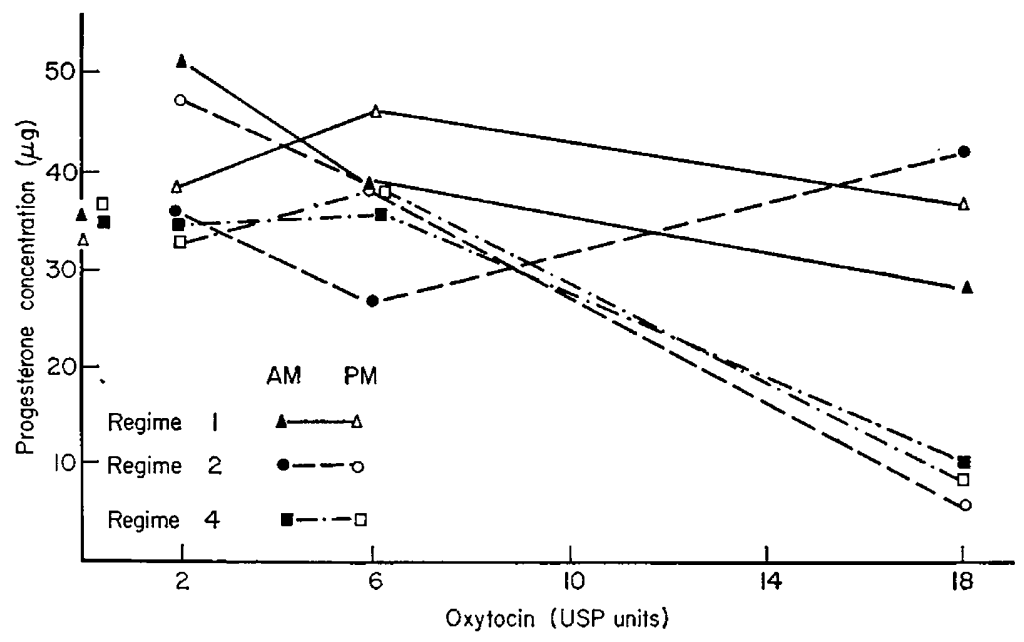

Text-FIG. 2. The dose-response relationships between corpus luteum progesterone concentration and dose of oxytocin injected a.m. or p.m. according to three injection regimes.

$(-2.596)$ was highly significantly less than the non-significant a.m. linear coefficient (0.627) (Text-fig. 2). In regime 4 , the linear coefficients for animals injected a.m. $(-1.683)$ and p.m. $(-1.727)$ were both equal and highly significant. Within a.m.-injected animals the linear coefficients for regimes 1 and 4 were equal and less than for regime 2 , at the $1 \%$ and $0.1 \%$ probability levels, respectively. Within p.m.-injected animals regimes 2 and 4 were equal and less than for regime 1 at $0.1 \%$ and $1 \%$ probability levels, respectively.

Within the high dose of oxytocin groups (18 units) there were significant differences in progesterone concentrations between regimes and times of injection. These are listed in Table 2, and graphed in Text-fig. 3. In regime 1, both the a.m. and p.m. progesterone concentrations were higher than in other groups except for the a.m. regime concentration, which itself was greater than other groups in regimes 2 to 4 . 
TABLE 2

MEAN GORPUS LUTEUM PROGESTERONE GONCENTRATIONS $(\mu \mathrm{G})$ FOR THE HIGH DOSE OF OXYTOGIN (18 UNITS) FOR EAGH TIME OF INJECTION $\times$ INJEGTION REGIME

\begin{tabular}{c|c|c|c|c}
\hline & \multicolumn{4}{|c}{ Injection regime } \\
$\begin{array}{c}\text { Time of } \\
\text { injection }\end{array}$ & 1 & 2 & 3 & 4 \\
\hline & $\begin{array}{c}28 \cdot 4^{c e} \\
41 \cdot 3^{a}\end{array}$ & $\begin{array}{c}42 \cdot 1^{a} \\
6 \cdot 7^{b d}\end{array}$ & $\begin{array}{r}10 \cdot 7^{b s} \\
9 \cdot 3^{b d}\end{array}$ & $\begin{array}{r}10 \cdot 0^{b d} \\
9 \cdot 6^{\text {bd }}\end{array}$ \\
\hline p.m.
\end{tabular}

Means with superscript $a$ significantly greater than means with superscript $b(P<0.001)$; means with superscript $c$ significantly greater than means with superscript $d(P<0.01)$; means with superscript $e$ significantly greater than means with superscript $f(P<0.05)$.

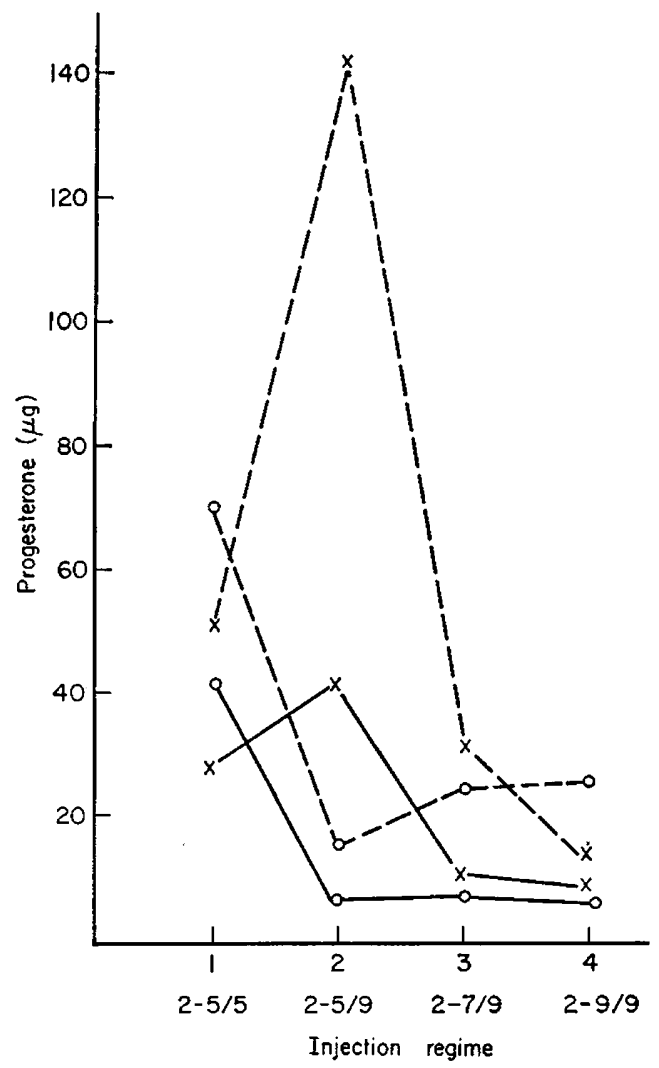

TEXT-FIG. 3. Relationships between corpus luteum progesterone concentration and total progesterone content $(----)$ and injection regime for the high dose of oxytocin (18 units) injected either a.m. $(x)$ or p.m. (0). 


\section{Corpus luteum total progesterone content}

In regime 1 the linear coefficients for a.m.- $(-2.057)$ and p.m.- $(-1.011)$ injected animals between total progesterone content and dose of oxytocin were equal and not significant. In regime 2, the a.m. linear coefficient $(-1.987)$ was not significant and greater $(P<0.001)$ than the highly significant p.m. linear coefficient $(-13 \cdot 819)$. In regime 4 both the a.m. $(-7 \cdot 566)$ and the p.m. $(-9 \cdot 159)$ linear coefficients were significant $(P<0.001)$ and equal (Text-fig. 4$)$.

Linear coefficients for a.m.-injected animals were equal for regimes 1,2 and 4. Linear coefficients for p.m.-injected animals were equal for regimes 2 and 4 and greater than the linear coefficient for regime $1(P<0.001$ and 0.05 respectively).

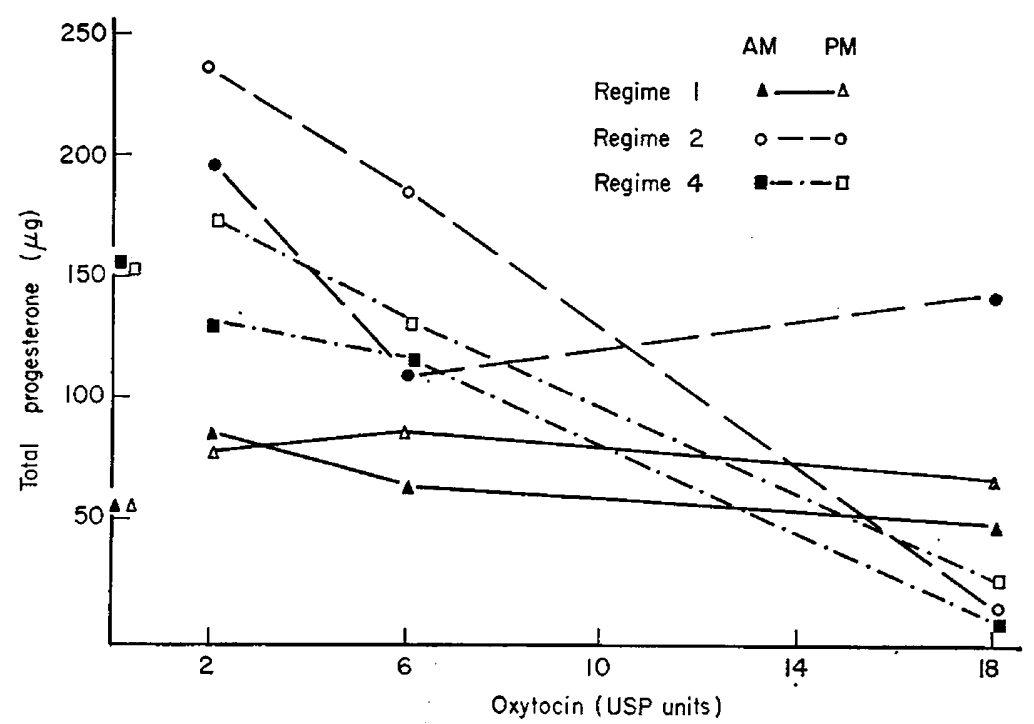

Text-Fig. 4. The dose-response relationships between corpus luteum total progesterone content and dose of oxytocin injected a.m. or p.m. according to three injection regimes.

Within the high dose of oxytocin group (18 units) there were significant differences in the total progesterone content between regimes and times of injection. These are listed in Table 3 and graphed in Text-fig. 3. In regime 2 the a.m. progesterone content is higher than all other groups. In regime 1 the p.m. is greater than the a.m. progesterone content and these are higher than those in other groups in regimes 2 to 4 .

When the responses at doses 2 and 6 were analysed separately from dose 18 the a.m. total progesterone content $(118.5 \mu \mathrm{g})$ was lower than the p.m. content $(151 \cdot 8)(P<0 \cdot 01)$.

\section{Comparison of dose rates of 0 and 2 units of oxytocin}

In regimes 1 and 4 the corpus luteum net weight, progesterone concentration and total progesterone content were the same in uninjected controls and animals injected with the 2 units dose rate of oxytocin. In regime 2 there were no 
differences in net weight and progesterone concentration, but total progesterone $(218.0 \pm 22.8 \mu \mathrm{g})$ was higher in those injected with the low dose of oxytocin than in the controls $(156 \pm 11.6 \mu \mathrm{g})(P<0.001)$.

\section{Returns to oestrus}

Nine heifers were detected in oestrus during the treatment period. Seven were animals injected p.m., two each from regimes 2 and 3 , and three from regime 4 . The two animals injected a.m. were one each from regimes 3 and 4 .

\section{Histology}

Histological examination of the corpora lutea did not reveal any departures from the general relationship described by Donaldson \& Hansel (1965) between structure and progesterone concentration.

TABLE 3

MEAN GORPUS LUTEUM TOTAL PROGESTERONE CONTENT $(\mu \mathrm{G})$ FOR THE HIGH DOSE OF OXYTOCIN (18 UNITS) FOR EACH TIME OF INJEGTION $\times$ INJECTION REGIME

\begin{tabular}{l|c|c|c|c}
\hline \multirow{2}{*}{$\begin{array}{c}\text { Time of } \\
\text { injection }\end{array}$} & \multicolumn{4}{|c}{ Injection regime } \\
\cline { 2 - 5 } & 1 & 2 & 3 & 4 \\
\hline a.m. & $50 \cdot 5^{c}$ & $143 \cdot 6^{d}$ & $32 \cdot 7^{d}$ & $15 \cdot 5^{d}$ \\
p.m. & $71 \cdot 1^{\mathrm{b}}$ & $18 \cdot 9^{d}$ & $25 \cdot 8^{d}$ & $27 \cdot 3^{d}$ \\
\hline
\end{tabular}

Mean with superscript a significantly greater than all other means $(P<0.001)$; mean with superscript $b$ significantly greater than means with superscript $c$ or $d$ and that with $c$ greater than $d(P<0.05)$.

\section{DISGUSSION}

A dose-response relationship was demonstrated between dose of oxytocin and parameters of corpus luteum function, under certain conditions. This relationship is most usefully discussed in terms of the total progesterone content of the corpus luteum, the product of net weight and progesterone concentration. No dose response in corpus luteum total progesterone content was measured when the oxytocin was injected on Days 2 to 5 and the measurement made on Day 5. However, there was a significant dose-response relationship when the measurement was delayed till Day 9 when oxytocin was injected p.m. but not a.m. The a.m. response in regime 2 was notable at the high dose rate of oxytocin (18 units) because the progesterone content of the corpus luteum was not reduced below Day 5 levels. At doses 2 and 6, a.m. injections had a larger effect on corpus luteum function than p.m. injections. These diurnal differences in response between the 2 and 6 units and the 18 units dosages of oxytocin cannot be explained but appear to be real differences.

The largest responses to oxytocin were obtained when the injections were 
made p.m. on Day 2 to Day 5 (but not with a.m. injections); or when a.m. or p.m. injections were made on Day 2 to Days 7 to 9 . There may be a critical time on Day 5 through which injections must be made to elicit a change in corpus luteum function as well as a diurnal variation in response to oxytocin. However, it may have been impossible to alter corpus luteum function in regime 1 , and a.m. regime 2, because the corpus luteum is refractory to the action of gonadotrophin (Donaldson et al., 1965), not because oxytocin is unable to effect pituitary gonadotrophin release.

Oxytocin injected at oestrus affects corpus luteum function and pituitary gonadotrophin content (Hansel et al., 1958; Donaldson et al., 1965) and injected on Days 12 and 13 oxytocin stimulates corpus luteum function (Mares \& Casida, 1963). It therefore seems that oxytocin can effect release of pituitary gonadotrophin at many stages of the cycle.

The stimulation of progesterone content (measured on Day 9) by the low dose $(2$ units) of oxytocin supported the hypothesis that oxytocin caused pituitary gonadotrophin release. Increase in dose rate of oxytocin or the number of injection days caused marked inhibition of corpus luteum function, which could be caused by depleted pituitary gonadotrophin levels or blocked or reduced gonadotrophin synthesis causing low blood plasma gonadotrophin levels. The fact that heifers will return to oestrus during oxytocin treatment with normal oestrus and ovulation (Armstrong \& Hansel, 1959) suggests that gonadotrophin synthesis is not affected and that pituitary gonadotrophin storage can occur during oxytocin treatment.

Corpus luteum function is not altered when oxytocin is injected into the hysterectomized cow (Armstrong \& Hansel, 1959; Anderson \& Bowerman, 1963). When oxytocin is injected as in this experiment uterine contractions are only transitory (Malven, personal communication), so that it is unlikely that oxytocin exerts its effects through uterine contractions. Although the release of a uterine luteolytic factor cannot be excluded, evidence to date supports a hypothesis that oxytocin could act through a hypothalamo-pituitary pathway shared commonly with the uterus. Hysterectomy may activate this pathway in such a way that it no longer responds to oxytocin. Corbin \& Schottelius (1961) showed that oxytocin hastened sexual maturation in intact or hypothalamic-lesioned immature female rats when oxytocin was dripped into the third ventricle, supporting the hypothesis of an action of oxytocin through the hypothalamo-pituitary pathway.

Ginther (1967) reported that oxytocin reduced oestrous cycle length in heifers when the uterine horn adjacent to the corpus luteum was left intact and the other horn was removed, but did not reduce cycle length when only the uterine horn adjacent to the corpus luteum was removed. Ginther's (1967) results indicate a local utero-ovarian mechanism and are not obviously compatible with the theory that oxytocin affects corpus luteum function through the pituitary gland. While realizing that experimental procedures such as Ginther's (1967) may introduce artificial mechanisms which are inconsistent with normal physiological functions, it seems that further and definitive experiments are necessary to resolve the problem of mode of action of oxytocin in altering corpus luteum function in the cow. 


\section{ACKNOWLEDGMENTS}

The authors are particularly appreciative of the technical assistance of $\mathrm{Mr} \mathrm{J}$. Leonard and $\mathrm{Mr}$ T. Magner. Part of the development of the technique for progesterone determination was done while the senior author was working in the laboratory of Professor W. Hansel, Cornell University, Ithaca, N.Y. His encouragement and the contributions of Dr K. Seifert are gratefully acknowledged. The help of Mr P. Haydock, who did the statistical analysis, is also appreciated.

The authors are appreciative of the assistance of the Australian Meat Research Committee which partially financed the experiment.

\section{REFERENCES}

ANderson, L. L. \& Bowerman, A. M. (1963) Utero-ovarian function in oxytocin treated heifers. (Abstract). F. Anim. Sci. 22, 1136.

Armstrong, D. T. \& HANSEL, W. (1959) Alteration of the bovine oestrous cycle with oxytocin. F. Dairy Sci. 42, 533.

Armstrong, D. T., O'Brien, J. \& Greep, R. O. (1964) Effects of luteinizing hormone on progestin biosynthesis in the luteinized rat ovary. Endocrinology, 75,488 .

Corbin, A. \& SchotTelius, B. A. (1961) Hypothalamic neurohormonal agents and sexual maturation of immature female rats. Am. F. Physiol. 201, 1176.

Donaldson, L. E. (1962) Some observations on the fertility of beef cattle in North Queensland. Aust. vet. 7. 38, 447.

Donaldson, L. E. \& Hansel, W. (1965) Histological study of bovine corpora lutea. 7. Dairy Sci. 48, 905.

Donaldson, L. E., Hansel, W. \& Van Vleck, L. D. (1965) Luteotropic properties of luteinizing hormone and nature of oxytocin induced luteal inhibition in cattle. F. Dairy Sci. 48, 331.

Ginther, O. J. (1967) Local utero-ovarian relationships. F. Anim. Sci. 26, 578.

Hansel, W., Armstrong, D. T. \& McEntee, K. (1958) Recent studies on the mechanism of ovulation in the cow. In: Proc. IIIrd Symp. Reprod. Infert., p. 63. Ed. F. X. Gassner, Pergamon Press, New York.

Mares, S. E. \& Casida, L. E. (1963) The effect of exogenous oxytocin on the progesterone content of the bovine corpus luteum. Endocrinology, 72, 78.

Simmons, K. R. \& Hansel, W. (1964) The nature of the luteotropic hormone in the bovine. F. Anim. Sci. 23, 136.

Staples, R. E. \& Hansel, W. (1961) Luteal function and embryo survival in the bovine. $\mathcal{F}$. Dairy Sci. 44, 2040.

Turner, C. D. (1960) General endocrinology, 3rd edn. Saunders, Philadelphia. 